\title{
As Relações entre Afetividade e Inteligência no Desenvolvimento Psicológico ${ }^{1}$
}

\author{
Maria Thereza Costa Coelho de Souza \\ Universidade de São Paulo
}

\begin{abstract}
RESUMO - Este texto apresenta considerações sobre as relações entre afetividade e inteligência no desenvolvimento psicológico, a partir de quatro modelos teóricos: as perspectivas psicogenéticas de Piaget, Wallon, Vygotsky e concepções extraídas da teoria psicanalítica de Freud. O objetivo é apontar as ênfases de cada abordagem para os aspectos afetivos e cognitivos e seu papel no desenvolvimento psicológico. Como conclusão, pode-se dizer que os modelos, interessados pela gênese da construção do conhecimento ou pela constituição do psiquismo, apresentam diferentes tipos de relação entre afetividade e inteligência. Uns propõem relações de alternância (Wallon); complementaridade de um em relação ao outro (Vygotsky) ou correspondência (Piaget) entre afetividade e inteligência, enquanto outro enfatiza aspectos pulsionais que interferem no funcionamento psicológico afetivo e cognitivo (Freud).
\end{abstract}

Palavras-chave: afetividade; inteligência; desenvolvimento psicológico

\section{Relations between Affectivity and Intelligence in Psychological Development}

\begin{abstract}
This text presents some considerations about the relations between affectivity and intelligence in psychological development, based on four theoretical models: the psychogenetic approaches of Piaget, Wallon, Vygotsky and some concepts from Freud's psychoanalysis theory. The main objective is to point out the emphasis of each approach regarding to affective and cognitive aspects and also their role in psychological development. What can be concluded is that the theoretical models, interested in knowledge construction or in psychic constitution, present different relations between affectivity and intelligence. Some of these propose relations of alternation (Wallon), relations based on one supplementing the other (Vygotsky) or on a correspondence between them (Piaget), while another focuses on pulsional aspects that interfere on affective and intellectual psychological functioning.
\end{abstract}

Keywords: affectivity; intelligence; psychological development

O tema das relações entre afetividade e inteligência, entre razão e emoção, foi herdado pela Psicologia, da Filosofia, como campo de reflexão sobre a natureza humana. Seriam as emoções desconhecidas pela razão confirmando a máxima de Pascal: "O coração tem razões que a própria razão desconhece". As emoções seriam exclusivamente prejudiciais ao funcionamento da racionalidade? Pode-se compreender as emoções com a mesma 'lógica' com que se compreende a razão? As 'paixões' do ser humano fazem parte de sua natureza e constituem um tipo particular de emoção desenfreada? E por isto, são primitivas? Há emoções conscientes? Pode-se falar em caráter emocional da inteligência?

As perguntas formuladas acima poderiam se multiplicar em muitas outras dependendo da ótica escolhida para sua análise e do modelo escolhido como referência teórica compreensiva. Neste texto serão tratadas as relações postuladas para a afetividade e a inteligência à luz de diferentes teorias psicológicas, a saber, as teorias psicogenéticas de Vygotsky, Wallon e Piaget

1 Este texto se refere à prova escrita para obtenção de título de Livre Docente, junto ao Departamento de Psicologia da aprendizagem, do desenvolvimento e da personalidade, do Instituto de Psicologia da USP, em novembro de 2007.

2 Endereço para correspondência: Departamento de Psicologia da aprendizagem, do desenvolvimento e da personalidade Av. Prof. Mello Moraes 1721, CEP 05508-900. Cidade Universitária. São Paulo. SP. Email:mtdesouza@usp.br e conceitos extraídos da teoria psicanalítica freudiana. Estas perspectivas foram escolhidas por tres razões principais. A primeira é que frequentemente estas abordagens são apontadas como privilegiando ou a inteligência ou a afetividade como únicos motores do desenvolvimento psicológico. A segunda razão é que articulações referentes às relações entre afetividade e inteligência, de acordo com estes modelos teóricos, são usualmente deixadas em segundo plano, o que pode levar a visões unilaterais sobre o desenvolvimento psicológico. Finalmente, a terceira razão é que há certa contemporaneidade histórica entre os autores e a construção dos modelos teóricos, o que confere alguma convergência às suas conceituações, mas também pontos importantes de divergência, interessantes para a discussão aqui pretendida.

Como ponto de partida para a apresentação do tema tomaremos a citação de Scherer (1993):

"A divisão platônica da psique humana em três partes, cognição, emoção e conação, marcou profundamente a representação que muitos psicólogos fazem da natureza humana. Esses três elementos são considerados como estruturas nitidamente delimitadas e parcialmente antagonistas, em aparência. Segue-se que a questão da prevalência da cognição ou razão sobre a emoção ou paixão- ou o inverso- é incessantemente colocada. Como pano de fundo, é o debate das convicções filosóficas fundamentais sobre a natureza humana, que determina as diversas orientações gerais da pesquisa psicológica." (p. 97-98) 
Scherer afirma também que a Psicologia do século XIX e do começo do século XX foi dominada pelos chamados instintivistas e irracionalistas, até que nos anos 60, a chamada 'revolução' cognitiva juntamente com a progressão do behaviorismo, provocaram uma visão racionalista do ser humano no que diz respeito à sua atividade, apresentando-o não mais como alguém que é escravo de suas paixões, mas como um "filósofo capaz de dedução lógica".

Interessa-nos para este texto justamente a idéia dessa transformação radical da concepção da natureza humana sobre a qual as diferentes teorias psicológicas se fundamentaram, especialmente aquelas que passaram a valorizar aspectos das experiências (do 'vivido') e do comportamento humano que não se harmonizavam com a imagem do homem lógico. Deste fato, decorreu uma concepção largamente difundida de que as emoções seriam "lamentáveis imperfeições da máquina cognitiva” (Scherer,1993, p. 98).

Voltaremos às afirmações de Scherer quando apresentarmos alguns modelos teóricos em Psicologia do Desenvolvimento quanto às suas ênfases e estatutos para os aspectos afetivos e intelectuais ou cognitivos, confrontando-os a título de reflexão teórica, já que os quatro modelos tiveram o início de sua construção no início do século XX (anos 20/30 para Piaget e Vygotsky; anos 40, para Wallon; 1897/1900, para a Psicanálise de Freud). Este último autor parece ser o único a se adequar à afirmação de Sherer sobre o predomínio da 'irracionalidade', ao menos no que se refere aos seus trabalhos iniciais sobre o inconsciente. A isto voltaremos mais adiante.

Para a exposição pretendida agrupamos numa seção, os modelos teóricos de Wallon, Vygotsky e conceitos extraídos da psicanálise de Freud, e, numa outra seção, as concepções de Piaget sobre as relações entre afetividade e inteligência. Esta organização se deve ao fato de considerarmos que a teoria piagetiana, se comparada às teorias psicogenéticas de Vygotsky e Wallon, parece ser a única a explicitamente apontar a idéia de uma correspondência constante entre aspectos afetivos e intelectuais em qualquer conduta, não apenas de maneira geral, mas em todas as fases do desenvolvimento (ainda que não tenha aprofundado a pesquisa empírica sobre esta correspondência). Para Wallon, a relação entre afetividade e inteligência é de alternância, podendo as primeiras emoções criar estruturações cognitivas e para Vygotsky, estas relações são de complementaridade, estando as emoções entendidas no âmbito das funções mentais, das quais o pensamento faz parte. No caso da psicanálise freudiana, além da discussão sobre se é uma teoria sobre a afetividade ou não, o que abordaremos em seguida, não parece ter o interesse de apontar relações entre afetividade e inteligência, mas muito mais submetê-los à teoria das pulsões. Como nos interessa aqui ressaltar o caráter de correspondência apontado por Piaget para estas relações, optamos por separar a apresentação da abordagem piagetiana das perspectivas de Wallon, Vygotsky e Freud.

\section{As relações entre afetividade e inteligência nas teorias psicogenéticas de Wallon, Vygotsky e na teoria de Freud}

Bussab e Souza (2006) em livro sobre a temática das relações entre razão e emoção iniciam o assunto, afirmando que as dicotomias presentes nas relações entre mente e corpo, razão e emoção, natureza e cultura, podem ser vantajosas para a apresentação didática de tema tão complexo, mas são insuficientes para sua compreensão integral. Os diferentes modelos psicológicos buscaram lidar com a dicotomia entre razão e emoção, inserindo entre elas relações de tipo causal ou de preponderância, o que redundou em denominações tais como teorias 'cognitivistas' ou teorias 'afetivas'. Denominações como essas, unilaterais, acabaram, ao longo do tempo, conferindo a alguns modelos uma espécie de 'posse' desses aspectos da natureza humana, de forma excludente, dando a impressão de que os elementos cognitivos e afetivos, partes integrantes do funcionamento psicológico dos indivíduos, poderiam ser tomados, cada um, como a totalidade do mesmo.

Podemos notar, então, que, para algumas abordagens a razão parece estar submetida à afetividade (conforme algumas interpretações do modelo freudiano, por exemplo), ou vice-versa (conforme algumas críticas feitas à abordagem piagetiana do assunto). Assim, consideramos muito importante rever os estatutos e os papéis atribuídos aos aspectos afetivos e cognitivos, nas diferentes teorias para empreender uma compreensão para além da visão dicotômica da natureza humana

Iniciaremos pela abordagem de Henri Wallon (18791962), a qual privilegia o aspecto afetivo, indicando seu papel estruturante no início da vida da criança. Para este autor, a emoção organiza a vida psíquica inicial e antecede as primeiras construções cognitivas. A gênese da cognição está, pois, para Wallon, nas primeiras emoções, as quais, por sua vez, estão diretamente ligadas ao desenvolvimento do tônus (aspecto orgânico). O mesmo autor define o desenvolvimento como a passagem do eu orgânico ao eu psíquico, pela via das primeiras emoções que são, em essência, o instrumento para a interação com o outro, antes que a cognição seja construída. Assim, as emoções permitem, no início da vida, a construção dos conhecimentos sobre o mundo e a construção da "personne" (traduzida para o português como 'personalidade', quando a tradução para 'pessoa' estaria mais condizente com o significado do conceito no modelo walloniano, ou seja, a idéia de 'eu'). Em obra clássica sobre o desenvolvimento psicológico (Wallon, 1941), o autor apresenta o que considera como a seqüência do desenvolvimento quanto à construção da pessoa a partir da idéia do papel estruturador das primeiras emoções em relação à cognição, para depois descrever o desenvolvimento como um movimento de alternância de predominâncias, ora afetiva ora cognitiva, culminando com uma preponderância cognitiva.

No início de sua vida a criança possui emoções que são independentes da representação, de acordo com Galvão (2003). Essas emoções iniciais são o recurso expressivo das necessidades por excelência, diferentemente dos sentimentos e paixões que dependem de representações. Para Galvão, a idéia essencial sobre a emoção na perspectiva de Wallon poderia ser resumida na frase: "a emoção se nutre do efeito que causa no outro" (Galvão, 2003, p. 77). A apreciação de Galvão está de acordo com as etapas da construção da pessoa postulada por Wallon, a saber: 1) etapa de indiferenciação entre eu e outro ou confusionismo (na qual as primeiras emoções fazem a comunicação e expressão das necessidades orgânicas); 2) diferenciação gradativa entre eu e outro com o despontar da 'pessoa' (inicialmente mais para se opor ao mundo na fase de oposição, para depois afirmar seu eu na 
fase do personalismo); e 3) chegando (aproximadamente na idade escolar) à fase categorial, na qual, já de posse de instrumentos cognitivos tais como a representação e o pensamento racional, utiliza-os para coordenar as emoções e para construir conhecimentos.

Vemos então que, para Wallon, as emoções podem inicialmente criar operações cognitivas que permitirão a construção do conhecimento, por um lado, e, por outro, podem estruturar a 'pessoa' no início da vida, sem a participação da cognição (nem mesmo a sensório-motora). Mais adiante veremos que Piaget se oporá a esta formulação de Wallon, preferindo pensar em relações de correspondência entre afetividade e inteligência e não em relações de causalidade e alternância.

Já a perspectiva de Vygotsky (1896-1934) propõe que a razão teria a capacidade de controlar as emoções mais primitivas, graças ao domínio dos instrumentos culturais, em especial a linguagem. Em obra que reúne conferências realizadas pelo autor no Instituto Pedagógico de Leningrado, Vygotsky aborda o desenvolvimento psicológico das funções superiores na infância, tais como memória, percepção, pensamento, imaginação e vontade. Quanto ao desenvolvimento do pensamento (conferência 3), retoma as idéias e experimentos de Hermann Ebbinghaus, psicólogo alemão, partidário do associacionismo, que começou a estudar a memória "livre de cultura", no âmbito das funções superiores e ressalta o caráter histórico da psicologia que buscava explicar o pensamento dirigido para um fim, desde o associacionismo que conduz ao behaviorismo, até a teoria estrutural (como por exemplo a teoria gestáltica), que seguiu o caminho contrário do behaviorismo, concebendo o pensamento como " uma forma primária de atividade, assim como a sensação." (Vigotski,1999, pp.54). Para o autor, as teorias que valorizaram o pensamento da criança no plano biológico deveriam (como fez Piaget ao ser ver) considerar simultaneamente os momentos sociais e biológicos no desenvolvimento do pensamento. No entanto, ao se referir à teoria de Piaget, nesta ocasião, Vygotsky a posiciona juntamente com a psicanálise de Freud, como se ambas se referissem ao pensamento como regido pelo principio do prazer ou, " dito de outra forma, que na idade precoce a criança pensa seguindo os mesmos motivos que a impulsionaram a realizar qualquer outra atividade, ou seja, sua satisfação.” (Vigotski, 1999, pp.60). Veremos posteriormente que quando Piaget se refere aos primeiros sentimentos na vida da criança, aqueles que se harmonizam com a estruturação sensório-motora, estes serão apresentados como ligados às percepções e às sensações fisiológicas, bem como ao êxito ou o fracasso nas ações, o que não significa interpretá-las como impulsionadas pelo principio do prazer como Freud apresentou. Vygotsky parece tomar como referência os trabalhos de Piaget nos quais o próprio autor se apóia nos escritos de Buhler sobre o pensamento irracional, chamado de autista, estes contemporâneos aos seus escritos, já que não poderia tomar, por uma lacuna histórica, a teorização de Piaget sobre o desenvolvimento da inteligência e sobre as relações entre afetividade e inteligência (décadas de 40 e 50). Na conclusão da conferência sobre o pensamento, Vygotsky afirma: "portanto, o que é central para toda a estrutura da consciência e para todo o sistema da atividade das funções psíquicas é o desenvolvimento do pensamento." (Vigotski, 1999, p.76)
Quanto ao papel das emoções no desenvolvimento, o autor apresenta duas correntes de ideias: a primeira que toma as emoções como tendo uma origem biológica, desde Darwin passando por Ribot e a psicologia alemã, o que teve como conseqüência o aparecimento da teoria das emoções. Cita James para quem "a fonte das emoções está nas reações orgânicas que acompanham nossos processos emocionais." (Vigotski, 1999, p.82) e para quem as emoções se diferenciam em inferiores e superiores (Vigotski, 2001). A segunda corrente busca a natureza psicológica das emoções e se relaciona fundamentalmente às concepções de Lewin e Claparède, este último, tendo separado experimentalmente os conceitos de emoção, sentimento e sua expressão exterior, em oposição à James.

De acordo com Oliveira e Rego (2003), Vygotsky apresenta uma solução monista para o problema das relações entre afetividade e cognição, apoiado, principalmente em Espinosa (1632-1677). Assim, diferencia emoções primitivas originais, tais como alegria, medo e raiva, das emoções ditas 'superiores' complexas, como, por exemplo, a melancolia e o respeito, apontando também que a qualidade das emoções sofreria mudanças à medida que o conhecimento conceitual e os processos cognitivos da criança se desenvolvem (Simão, 2004).

Chegamos ao ponto central, de acordo com nosso ponto de vista, da formulação vygotskyana sobre as relações entre afetividade e cognição, lembrando que este autor teve como objeto de estudo a consciência humana, diferentemente de Wallon, Piaget e Freud. Concordamos com Oliveira (1992) e Gonsalez-Rey (2004) quando afirmam que a afetividade, na teoria de Vygotsky, se liga à singularidade dos sujeitos, tendo, pois, uma dimensão pessoal e subjetiva. Piaget formulou concepção em certa medida semelhante ao tratar a afetividade como mais ligada aos conteúdos singulares das condutas dos indivíduos do que à sua forma (estrutura) universal, ainda que tenha pensado em fases para o desenvolvimento da afetividade, correspondentes às do desenvolvimento da inteligência. Este aspecto será retomado mais adiante.

$\mathrm{O}$ ponto onde se encontram afetividade e inteligência, para Vygotsky, é na palavra, quanto aos seus dois componentes essenciais: o significado e o sentido. Sabemos que o estudo das funções cognitivas superiores tomando como referência a intervenção da mediação cultural, especialmente aquela propiciada pela linguagem e tendo como objeto de estudo a consciência humana, foi o foco de Vygotsky. Encontraremos como destaque em suas formulações a conceituação de 'palavra', bem como a de 'pensamento verbal'. Estas ilustram as articulações de idéias e as ênfases conceituais internas a este modelo teórico. Voltemos à palavra, que nos interessa no contexto das relações entre afetividade e inteligência. Não abordaremos o conceito de pensamento verbal mais detidamente neste texto, reservando-o para a discussão das relações entre pensamento e linguagem, que não é nosso objetivo aqui. A palavra possui, então, dois elementos: o significado e o sentido. O primeiro refere-se a um sistema de relações objetivas que formam uma espécie de núcleo estável, o qual pode ser compartilhado com outros indivíduos do mesmo grupo cultural. O significado está, assim, para Vygotsky, mais relacionado ao desenvolvimento dos processos cognitivos superiores. O sentido, por sua vez, se refere ao significado para cada indivíduo, que está, portanto, diretamente relacio- 
nado às suas vivências particulares, sendo assim o pólo mais afetivo da palavra. A palavra reúne, então, de acordo com a teoria vygotskyana, subjetividade e intersubjetividade, razão e emoção, afetividade e cognição, constituindo relações de complementaridade e não de causalidade ou alternância como pretendia Wallon.

Dissemos anteriormente que a teoria freudiana talvez fosse a única a se adequar à afirmação de Scherer sobre o predomínio de "abordagens instintivistas e irracionalistas" na ciência psicológica no final do século XIX e início do século XX. Ao apresentar seus primeiros escritos psicanalíticos em 1897 e 1900 (Estudos sobre a histeria e $A$ interpretação dos sonhos), o 'pai' da Psicanálise pretendeu demonstrar que o ser humano podia também ser determinado por aspectos desconhecidos à sua consciência, seus impulsos (pulsões). Esses elementos estranhos à razão eram, portanto, de outra ordem. Seria esta outra ordem afetiva? A psicanálise propõe uma teoria da afetividade?

É importante ressaltar que para Freud os afetos estão sempre ligados aos impulsos, não utilizando quase nunca a denominação 'afetividade', ou 'sentimento' (apenas para sentimento de culpa e sentimento de vergonha), ou ainda 'emoção'.

Afirmam Laplanche e Pontalis (1967/1977) sobre a palavra 'afeto', na obra de Freud: "afeto é um estado afetivo penoso ou agradável, vago ou qualificado... Toda pulsão (equivalente de impulso) se exprime nos dois registros: o do afeto e o da representação... o afeto é a expressão qualitativa da quantidade de energia pulsional e de suas variações.” (p.34)

Ao apresentar id, ego e superego em texto Freud (1923) apresenta a inteligência como uma das funções do ego articulada ao funcionamento, pelos processos secundários, à capacidade de síntese e aos mecanismos de defesa contra a angústia. Parece que a inteligência ainda que compareça como uma das funções do ego, não tem um papel importante na dinâmica entre o ego, a realidade, os impulsos do id e as pressões do superego. Parece-nos então que a teoria freudiana é nitidamente uma teoria dos impulsos, muito mais do que uma teoria da inteligência ou do funcionamento mental consciente. Não parece também ser esta teoria uma teoria da afetividade em seu sentido estrito, como o que é referido pelas teorias de Vygotsky e Wallon já apresentadas e a teoria de Piaget quanto às concepções que serão expostas a seguir. Se tivermos que estabelecer para o modelo freudiano uma tendência quanto às relações entre afetividade e inteligência, diríamos que se trata de uma relação de preponderância dos impulsos inconscientes sobre o funcionamento cognitivo e afetivo consciente.

\section{As relações entre afetividade e inteligência para Jean Piaget}

Piaget (1896-1980) é classicamente um autor relacionado ao desenvolvimento da inteligência, em seus aspectos lógico-matemáticos. A sequência de estágios do desenvolvimento do pensamento postulada pelo autor é bastante conhecida e parece ter sido certamente seu foco de estudo e pesquisa na grande maioria de seu tempo de vida e obra. No entanto, o mesmo autor apresentou por diversas vezes suas concepções sobre afetividade e sentimentos em suas relações com a evolução cognitiva, dos esquemas motores às operações formais, passando pelas representações pré-operatórias e operações concretas. O que disse Piaget sobre afetividade? Vejamos a seguinte citação:

\section{"É indiscutivel que o afeto tem um papel essencial no funciona- mento da inteligência. Sem o afeto não haveria nem interesses, nem necessidades, nem motivação; em conseqüencia, as inter- rogações ou problemas não poderiam ser formulados e não haveria inteligência. O afeto é uma condição necessária para a constituição da inteligência. No entanto, em minha opinião, não é uma condição suficiente." (Piaget, 1962/1994, p.129)}

Pretendemos demonstrar que as concepções de Piaget são muito mais do que 'opiniões' ou idéias desarticuladas, mas, ao contrário expressam uma formulação sobre as relações entre afetividade e inteligência que está para além de uma visão dicotômica sobre o ser humano, uma vez que propõe relações de correspondência entre a evolução cognitiva e a afetiva, superando as formulações causais e de complementaridade de outras abordagens.

A apresentação mais completa do assunto se deu no contexto de um curso proferido na Sorbonne em 1953-54 sobre as relações entre afetividade e inteligência no desenvolvimento da criança. Nesta ocasião, Piaget pretendeu retomar algumas proposições sobre os aspectos psicológicos das condutas apresentando sua formulação de correspondência e finalizando com a sua proposição de compreensão da moralidade na criança, ou seja, como uma intersecção entre elementos intelectuais, afetivos e sociais. Neste texto serão destacados os conceitos principais que subsidiam a formulação piagetiana.

Iniciemos pelas concepções de interesse e valor, apoiados em concepções de E. Claparède. Para este último, toda conduta possui dois elementos: 1) a meta ou finalidade (ou ainda intenção) mais ou menos consciente e que é definida pela afetividade; e 2) a técnica, que é o conjunto de meios empregados para atingir a meta e é determinada pelas funções cognitivas.

Ainda que tenha considerado o 'esquema' de Claparède simplificado demais, já que haveria elementos cognitivos nas metas e elementos afetivos nas técnicas, Piaget utilizará as concepções desse autor para compor a sua, associando os interesses às metas e conferindo à afetividade a qualidade 'energética' da conduta. Pierre Janet já tinha utilizado a idéia de força psicológica para referir-se à regulação energética da conduta que teria como critério principal o custo de energia.

Piaget considerou que se deveria agregar ao sistema regulador proposto por Janet o sistema de interesses, proposto por Claparède, chegando à concepção de 'valor', a qual norteia e perpassa toda a sua proposição. Algumas definições de valor apontadas por Piaget: 1) valor é a expansão da atividade do eu na conquista do universo; 2) valor é o intercâmbio afetivo com o exterior (objeto ou pessoa); e 3 ) valor é o aspecto qualitativo do interesse. E mais: os valores atribuídos às pessoas são o ponto de partida para os sentimentos. Piaget concorda com Claparède e sintetiza sua tese; toda conduta é ditada por um interesse, que se relaciona a uma meta para a ação. Estes interesses se revelam sob a forma de valores e são constituídos em essência pela afetividade. Os meios que 
permitirão atingir a meta serão constituídos pela inteligência. Em síntese, A vida afetiva como a vida intelectual é adaptação contínua e as duas adaptações não são somente paralelas, mas interdependentes, visto que os sentimentos exprimem os interesses e os valores das ações, das quais a inteligência constitui a estrutura. (Piaget, 1945)

Piaget utiliza assim concepções apoiadas em formulações de Claparède, Janet e também Lewin (a noção de campo total com elementos intelectuais e afetivos) para formular sua tese: a de que toda conduta possui um elemento energético (afetivo) e um elemento estrutural (intelectual) que se relacionam mutuamente e que possuem naturezas diferentes. Empreende também uma articulação com a teoria psicanalítica quanto ao tema da escolha de objeto, afirmando que a evolução cognitiva no período sensório- motor que vai da indiferenciação entre eu e mundo; passando pelo egocentrismo e chegando à descentração (física, nesse caso), poderia ser análoga à evolução apresentada por Freud, do adualismo inicial, passando pelo narcisismo e chegando à primeira escolha de objeto do bebê, no período de zero a dois anos. Tal correspondência entre a proposição piagetiana e a freudiana foi pesquisada especialmente por Gouin-Décarie (1968). Esta pesquisadora canadense pretendeu, em sua investigação, aproximar os estágios da construção do objeto, segundo Piaget, do desenvolvimento das primeiras relações de objeto, a partir da psicanálise freudiana. Em seu trabalho, elaborou uma escala das relações objetais que está em consonância com as fases da construção do objeto, para Piaget. Gouin-Décarie propôs, assim, relações de correspondência entre o desenvolvimento das relações objetais e a construção do objeto permanente.

Tomando a idéia de correspondência como pano de fundo, Piaget apresenta sua proposição própria para as relações entre afetividade e inteligência, desta vez, sem utilizar outro modelo como referência. Sinteticamente faz corresponder à evolução do período sensório-motor, o que denominou afetos perceptivos, etapa na qual a afetividade, assim como a inteligência, está ligada às necessidades fisiológicas e às 'novidades' trazidas pelo exercício da percepção. São basicamente sentimentos de agrado e desagrado, êxito e fracasso, decorrentes das ações no mundo. Na etapa subseqüente, a das representações pré-operatórias, na qual predominam a imitação, o jogo simbólico e as intuições rígidas e inflexíveis, ocorreriam sentimentos também de natureza intuitiva (as simpatias e antipatias), rígidos e inflexíveis, bem como sentimentos ligados às pessoas como objetos privilegiados (o que não ocorria antes), ainda que falte à afetividade, assim como à inteligência, maior flexibilidade e conservação, mesmo que os afetos tenham já certa estabilidade. Os afetos são, entretanto, mais estáveis do que no período anterior.

Quando a inteligência se torna operatória trazendo enorme avanço no sentido da reversibilidade e flexibilidade do pensamento, permitindo a descentração cognitiva, a afetividade também evolui passando a se regular em sistemas de valores hierarquizados, bem como coordenando conflitos entre tendências de forças diferentes. Nesse período, os sentimentos se tornam normativos incorporando em sua dinâmica, as regras, a reciprocidade de interesses e os valores. Ao apresentar este processo de desenvolvimento da afetividade, Piaget introduz o conceito de força de vontade como regulação superior, isto é, como uma força que regula tendências de valências diferentes (fortes e fracas), organizando-as em sistemas de valores. Desta 'regulação superior' resulta a priorização das valorizações, num sistema móvel, o qual também se relaciona à noção de dever. No apogeu postulado para o pensamento, ou seja, quando as operações formais são construídas, permitindo o desligamento do real, por um lado, e, simultaneamente, sua submissão ao universo do possível, a afetividade se desloca das pessoas e das normas enquanto objetos, para as teorias e ideais que o pensamento pode agora constituir. São os denominados sentimentos ideológicos que concluem a evolução concebida por Piaget para a afetividade, em correspondência ao desenvolvimento da inteligência. Assim sendo, afetividade e inteligência seriam pólos indissociáveis na conduta, mas possuem papéis diferentes, caminhando juntas, conferindo às ações a dupla caracterização estrutural e energética.

A partir do que foi sinteticamente exposto, vemos que, de acordo com as ênfases de cada um dos modelos apresentados, haverá como continuidade, um método mais adequado para a pesquisa das relações entre afetividade e inteligência. No caso da perspectiva de Wallon, é importante focalizar as interações entre sujeito e objetos, destacando dentre estes objetos, o outro que se emociona, e que permite a gênese das primeiras cognições e a construção dos conhecimentos pela criança. Trata-se então, de destacar os detalhes das interações sociais, as emoções que se expressam nas ações e nas palavras daqueles que delas participam, adultos e crianças. Nesse caso, procedimentos tais como filmagens em vídeos, com recortes de interações consideradas significativas, são frequentemente utilizados. Cenas são apontadas como ilustrativas de regularidades interativas. Já se a abordagem subjacente for a vygotskyana, a ênfase estará nas relações histórico-culturais expressas especialmente na linguagem da criança e também do adulto, relações essas que terão influência tanto no desenvolvimento como na aprendizagem; afetividade estará diretamente ligada às subjetividades dos envolvidos nas interações, permeadas e transformadas pela cultura em suas diferentes manifestações, assim como transformando-a reciprocamente. $\mathrm{O}$ estudo da linguagem, da palavra e das narrativas como resultado das relações de reciprocidade entre sujeito e objeto, da complementaridade entre afetividade e racionalidade, será privilegiado neste contexto. Se, ao invés disso, a abordagem for piagetiana, o método de entrevistas elaborado por Piaget será o procedimento privilegiado no sentido de propor assuntos para a reflexão da criança, assim como para a sua valorização (afetiva) e organização de interesses, o que expressará as relações entre afetividade e inteligência. Os interesses e valorações têm, como vimos, o papel motivador, ao lado do papel estruturante exercido pela inteligência. Assim, a pesquisa sobre as crenças e teorias infantis necessariamente deverá contemplar elementos ligados aos conteúdos (valores) das condutas (contextuais, por exemplo).

Sabemos que o método da psicanálise, desde Freud, no que tange às relações entre os impulsos e o funcionamento consciente, é interpretativo, a partir da relação transferencial entre o paciente e seu analista. A pesquisa converte-se, então, na procura dos significados inconscientes para as manifestações conscientes, sejam afetivas e/ou cognitivas. Vimos neste texto que, do ponto de vista teórico, o modelo 
freudiano adota ênfases distintas das assumidas pelas teorias psicogenéticas de Wallon, Vygotsky e Piaget. Esta diferença de proposição é essencial e se reflete no método de pesquisa psicanalítica sobre as relações entre afetividade e inteligência. Assim sendo, não é possível diferenciar as abordagens apenas em seus métodos, mas também e principalmente em suas proposições epistemológicas.

Podemos chegar então à conclusão deste texto, retomando as afirmações que nos serviram de base quanto à divisão platônica do ser humano em três elementos: razão, emoção e conação (predisposição para a ação). Este último elemento não foi tratado aqui. No entanto, consideramos que a Psicologia só pode ter acesso aos elementos racionais e afetivos por meio do que aparece aos olhos do estudioso ou pesquisador, ou seja, a predisposição para a ação ou até mesmo a ação ou o comportamento propriamente ditos. Quanto às tentativas para superar a dicotomia entre razão e emoção consideramos que os modelos apresentados fazem face ao desafio, ao estabelecerem diferentes estatutos para estes aspectos indicando a necessidade de ambos para a compreensão da natureza humana, suas naturezas e papéis no funcionamento mental. Ao fazerem isto, são muito férteis em permitir formulações de pesquisas sobre esta complexa temática. A superação da dicotomia entre razão e emoção virá, então, com reflexões teóricas integradas, como a que pretendemos realizar aqui, mas também a partir dos resultados de investigações empíricas apoiados nos modelos teóricos de base e harmonizados com seus pressupostos epistemológicos.

Ao encerrar esta exposição, deve ser feito um último comentário sobre a afirmação inicial de Scherer, que indicou as proposições "instintivistas e irracionalistas" como preponderantes no final do século XIX e começo do século XX. Foi dito que esta afirmação parece se aplicar à psicanálise de Freud, ou ao menos às suas primeiras formulações sobre as características do inconsciente. Entretanto, talvez possa também se aplicar, de modo inverso aos escritos de Piaget que privilegiaram os aspectos racionais do funcionamento da inteligência. Não parecem se aplicar, contudo, nem aos seus escritos iniciais sobre o pensamento irracional das crianças (como bem apontou Vygotsky) e muito menos às suas últimas obras, as quais buscaram manter o dinamismo do funcionamento psicológico, em seus aspectos racionais e afetivos. Esperamos ter demonstrado que a referida afirmação não parece aplicar-se nem à teoria vygotskyana nem à formulação walloniana sobre o desenvolvimento psicológico.

Cremos ser pertinente encerrar estas considerações com a retomada da afirmação de Piaget: "O afeto é uma condição necessária para a constituição da inteligência; no entanto, em minha opinião, não é uma condição suficiente." (Piaget,1962/1994, p.129)

\section{Referências}

Bussab, V. S. R., \& Souza, M. T. C. C. de (2006). Apresentação. In V. S. R. Bussab \& M. T. C. C. Souza (Eds.), Razão e emoção: diálogos em construção (pp.7-12). São Paulo: Casa do Psicólogo.

Freud, S. (1972). Estudos sobre a histeria. Rio de Janeiro: Imago. (Obra publicada originalmente em 1897)
Freud, S. (1972). A interpretação dos sonhos. Rio de Janeiro: Imago. (Obra publicada originalmente em 1900)

Galvão, I. (2003). Expressividade e emoções segundo a perspectiva de Wallon. In V.A. Arantes \& J. G. Aquino (Eds.), Afetividade na escola. Alternativas teóricas e práticas (pp. 71-88). Campinas, SP: Ed. Summus.

Gonzalez-Rey, F. (2004). O sujeito, a subjetividade e o outro na dialética complexa do desenvolvimento humano. In L. M. Simão \& A. M. Martinez (Eds.), O outro no desenvolvimento humano. Diálogos para a pesquisa e a prática do profissional em psicologia (pp. 1-27). São Paulo: Pioneira Thomson Learning.

Gouin-Décarie, T. (1968). Intelligence et affectivité chez le jeune enfant. Neuchâtel: Delachaux et Niestlé.

Aplanche, J., \& Pontalis, J-J. (1977). Vocabulário de Psicanálise. Lisboa: Moraes Editores

Oliveira, M. K. (1992). O problema da afetividade em Vygotsky. In Y. de La Taille, M. K. Oliveira, \& H. Dantas (Eds.), Piaget, Vygotsky, Wallon. Teorias psicogenéticas em discussão (pp.7584). São Paulo: Summus.

Oliveira, M. K. \& Rego, T. (2003). Vygotsky e as complexas relações entre cognição e afeto. In V. A. Arantes \& J. G. Aquino (Eds.), Afetividade na escola. Alternativas teóricas e práticas (pp.13-34). São Paulo: Summus.

Piaget, J. (1926). La representation du monde chez l'enfant. Neuchâtel: Delachaux et Niestlé

Piaget, J. (1945). La formatiom du symbole chez l'enfant. Paris : P.U.F.

Piaget, J. (1954). Les relations entre l'affectivité et l'intelligence dans le dévéloppement de l'enfant. Bulletin de Psychologie, 7, 69-71; 143-150; 522-523.

Piaget, J. (1994). La relación del afecto com la inteligência en el desarrollo mental del niño. In G. Delahanty, \& J. Perrés (Eds.), Piaget y el psicoanálisis (pp. 181-289). Universidad Autónoma Metropolitana: Xochimilco. (Trabalho original publicado em 1962).

Piaget, J. (1968)- Préface. In T. Gouin Décarie (Ed.), Intelligence et affectivité chez le jeune enfant (pp 5-8). Neuchâtel: Delachaux et Nistlé.

Scherer, K. R. (1989/1993). Les émotions: fonctions et composantes. In K.R. Scherer \& B. Rimé (Eds.), Textes de base en Psychologie. Les emotions (pp. 97-129). Neuchâtel: Delachaux et Niestlé.

Simão, L. M. (2004). Alteridade no diálogo e construção do conhecimento. In L.M. Simão \& A. M. Martinez (Eds.), $O$ outro no desenvolvimento humano. Diálogos para a pesquisa e prática profissional em psicologia (pp.29-39). São Paulo: Pioneira Thomson Learning.

Vygotsky, L. S. (1999). O desenvolvimento psicológico na infância. São Paulo: Martins Fontes.

Vygotsky, L. S. (2001). Psicologia pedagógica. São Paulo: Artmed Wallon, H. (1941). L'évolution psychologique de l'enfant. Paris: Armand Colin.

Recebido em 27.04.2009

Primeira decisão editorial em 03.02.2010

Versão final em 01.03.2010

Aceito em 10.03.2010 